\title{
Por que Dilma de novo? Uma análise exploratória do Estudo Eleitoral Brasileiro de 2014
}

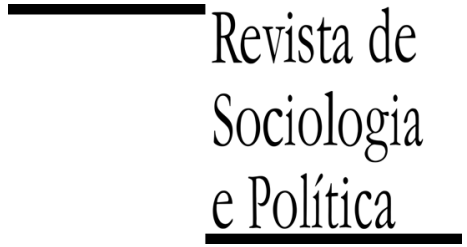

DOI 10.1590/1678-987315235605

\author{
Oswaldo E. do Amaral e Pedro Floriano Ribeiro
}

\begin{abstract}
Resumo
O artigo propõe uma análise exploratória acerca dos determinantes do voto para presidente nos dois turnos de 2014, com base nos resultados do Estudo Eleitoral Brasileiro (ESEB). A partir dos achados mais relevantes da ampla literatura recente sobre o tema, esboçamos um modelo geral de explicação do voto para presidente, com 15 variáveis que cobrem explicações contextuais, sociodemográficas, de avaliação retrospectiva/prospectiva, sociotrópica/egotrópica e de identidade política. As variáveis foram inseridas em um modelo logístico multinomial, no primeiro turno (voto em Dilma, Aécio ou Marina), e em um modelo binário no segundo turno (voto em Dilma ou Aécio). Os resultados apontam o caráter retrospectivo do comportamento do eleitor na última eleição presidencial: a avaliação em relação à gestão de Dilma Rousseff se mostrou um ótimo preditor do voto, em ambos os turnos. O julgamento sobre o desempenho do governo esteve dissociado, no entanto, da avaliação sobre a situação econômica do país, sugerindo que a percepção sobre outras políticas públicas deve ter impulsionado a avaliação positiva da gestão. A identificação partidária se confirmou como importante atalho cognitivo, o Bolsa Família teve efeitos significativos apenas no segundo turno e as variáveis sociodemográficas se mostraram pouco relevantes. O caráter retrospectivo do comportamento do eleitor, recompensando ou punindo o candidato do governo a partir da análise de seu desempenho, mostra-se um fator mais complexo do que se supunha, na medida em que não se restringe à avaliação do cenário econômico ou à participação direta nos programas de transferência de renda.
\end{abstract}

PALAVRAS-CHAVE: ESEB; eleições presidenciais de 2014; comportamento eleitoral; voto; Dilma Rousseff.

Recebido em 26 de Junho de 2015. Aceito em 13 de Agosto de 2015.

\section{Introdução ${ }^{1}$}

\footnotetext{
${ }^{1}$ Este artigo é um dos resultados do projeto "Organização e funcionamento da política representativa no Estado de São Paulo (1994 e 2014)", sediado no CESOP/UNICAMP e que conta também com pesquisadores da UFSCar, UNESP e USP. A pesquisa é financiada pela FAPESP (Projeto 12/19330-8). Agradecemos aos demais pesquisadores do projeto e aos pareceristas da Revista de Sociologia e Política pelas críticas e sugestões.
}

$\mathrm{N}$ os últimos anos, houve um grande avanço da literatura no sentido de explicar os determinantes do voto no Brasil, com destaque para estudos sobre o comportamento do eleitor na disputa presidencial. Essa literatura tem oscilado entre modelos estatísticos apoiados em dados agregados em nível municipal ou estadual, mobilizando variáveis como o Índice de Desenvolvimento Humano Municipal (IDH-M), a cobertura do Programa Bolsa Família (PBF, daqui em diante), o PIB per capita etc., e modelos explicativos assentados sobre dados em nível individual (surveys), explorando o rendimento de variáveis socioeconômicas, atitudinais e de inclusão em programas sociais como determinantes do voto.

Com dados individuais ou agregados, parte dessa literatura se debruçou sobre a transformação das bases eleitorais do PT e de Lula, ressaltando a inflexão entre 2002 e 2006 em direção a um eleitorado de perfil mais "popular" e mais disseminado pelo país. Em influente artigo, Hunter e Power (2007), partindo da análise de dados eleitorais agregados e de surveys, indicaram que a expansão de políticas sociais, em especial o PBF, teve importante efeito no resultado das eleições presidenciais de 2006, provocando a inversão da base de apoio do candidato petista. Nicolau e Peixoto (2007), ao observarem os resultados eleitorais em 2002 e 2006 nos municípios, chegaram a conclusões semelhantes, apontando para o impacto do PBF na mudança das bases geográficas do 
voto de Lula. Essa análise, que destaca a maior penetração do petista em regiões antes refratárias à sua candidatura, como o Norte e o Nordeste, foi confirmada por Terron e Soares (2010) que, a partir de estudo baseado em modelos geoespaciais, concluíram que o PBF teve impacto significativo na vitória de Lula em 2006. Para os autores, teria havido um divórcio entre as bases eleitorais do partido e de seu maior líder.

Zucco (2008), também a partir da análise de resultados eleitorais em nível municipal, encontrou os mesmos padrões de mudança. O autor, no entanto, estendeu o argumento e defendeu que as mudanças na base eleitoral das candidaturas petistas à presidência não fazem parte de uma transformação de longo prazo nas preferências políticas, mas simplesmente refletem o fenômeno do "governismo", em que eleitores de regiões mais pobres tendem a apoiar o candidato do governo - independentemente de sua coloração partidária e ideológica - por dependerem de recursos federais de vários tipos. Em artigo recente, em que ampliou a análise para o pleito presidencial de 2002, Zucco (2013) demonstrou que programas de transferência de renda também beneficiaram o então candidato José Serra (PSDB), fortalecendo o argumento levantado no seu trabalho anterior. Usando dados individuais, Licio, Rennó e Castro (2009) encontraram associação entre ser beneficiário do PBF e ter votado em Lula nas eleições de 2006. Partindo da mesma base de dados, mas com um modelo estatístico distinto, Bohn (2011) refutou essa interpretação e argumentou que a mudança na base eleitoral de Lula foi mais gradual do que a maioria dos trabalhos indicam.

A partir da análise sistemática de dados em nível individual, uma série de autores identificou a avaliação do governo e a situação da economia como elementos fundamentais para a escolha do eleitor nas eleições presidenciais brasileiras (Carreirão 2002; 2007; Nicolau 2007; Rennó 2007; Holzhacker \& Balbachevsky 2007; Rennó \& Cabello 2010; Peixoto \& Rennó 2011; Nicolau 2014a; 2014b). Segundo Meneguello (2007), esse foi um fenômeno comum em processos de redemocratização e, no Brasil, contribuiu para a consolidação de alternativas partidárias e da polarização nas disputas presidenciais entre os candidatos do PT e do PSDB. Em perspectiva comparada, Veiga (2013) confirma a importância do voto econômico em 18 países da América Latina entre 1995 e 2010. A percepção subjetiva sobre a economia, mais do que o desempenho objetivo em termos de crescimento, inflação etc., tem impacto significativo sobre a decisão de voto na eleição presidencial - mas não na eleição legislativa. Ao incorporar ao modelo também a avaliação do eleitor sobre as perspectivas econômicas futuras do país - voto sociotrópico prospectivo - a autora não encontrou associação significativa: a avaliação sobre o desempenho passado fala mais alto ao eleitor do que a projeção que ele faz sobre o futuro.

Trilhando outro caminho, Singer (2009) aponta as conexões entre o pertencimento a uma classe social e a decisão de voto do eleitor brasileiro nos últimos anos. Os trabalhos de Carreirão e Kinzo (2004), Braga e Pimentel Jr (2011), Ribeiro, Carreirão e Borba (2011) e Nicolau (2014b) defenderam a importância da preferência partidária na definição do voto, ressaltando o papel dos partidos na estruturação das preferências eleitorais. Na conclusão de seu estudo que utilizou dados do ESEB 2010, Ribeiro, Carreirão e Borba (2011, p.362) afirmam: "No que diz respeito à decisão do voto, embora no Brasil não haja consenso sobre o papel dos partidos, os nossos resultados parecem indicar que eles representam um atalho informacional relevante para os eleitores, pelo menos nas eleições presidenciais".

As análises das eleições presidenciais de 2010 confirmaram alguns dos padrões encontrados anteriormente e adicionaram novas hipóteses para a definição do voto do brasileiro. A partir de dados coletados no ESEB 2010, Peixoto 
e Rennó (2011), em análise bastante abrangente, demonstraram que "a avaliação do governo, o voto em Lula nas eleições anteriores e a identificação partidária continuam sendo explicações sólidas para as escolhas eleitorais feitas por eleitores brasileiros" (idem, p.323). Ou seja, a candidata Dilma Rousseff se beneficiou dos altos níveis de aprovação do governo e do apoio dos eleitores a Lula e ao PT; ser beneficiário do PBF, no entanto, não pesou sobre a decisão do eleitor. Os autores encontraram também impactos determinados pela denominação religiosa: eleitores evangélicos tenderam a votar em oposição à candidata do governo. $\mathrm{O}$ achado mais relevante dos autores, porém, foi sobre o papel da autopercepção do eleitor acerca da mobilidade social no período Lula (2003-2010) como determinante do voto. Em lugar do voto econômico do tipo sociotrópico (avaliação retrospectiva da situação econômica do país), grande parte do eleitorado agiu conforme uma racionalidade retrospectiva egotrópica, recompensando as forças políticas que ele julgava como responsáveis por sua ascensão social pessoal. Assim, indivíduos que se julgavam em posição social mais favorável que antes tenderam fortemente a votar em Dilma.

Já em trabalho recente, Nicolau (2014b) apontou o efeito de uma variável contextual - a região - sobre o comportamento do eleitor. Morar no Nordeste aumentou a probabilidade do voto em Dilma Rousseff no primeiro turno com relação a José Serra, candidato do PSDB, mantidas todas as outras variáveis constantes. Além disso, o autor encontrou também impactos provocados por variáveis sociodemográficas, como a escolaridade.

Nesta breve revisão, destacamos como a decisão do voto nas eleições presidenciais brasileiras pode ser tratada de maneira multidimensional, com variáveis de distintas naturezas impactando na escolha do eleitor. Grosso modo, os principais fatores que têm se sustentado como mais significativos ao longo do tempo, perpassando trabalhos com fontes de dados e tratamentos estatísticos variados, são a avaliação do governo e do presidente, a percepção do eleitor sobre o cenário econômico e os programas de transferência de renda - este último com algumas controvérsias em relação a seus significados e impactos eleitorais. À exceção de Singer (2009), que envereda por explicações calcadas em fatores como classe social e ideologia, recuperando variáveis próprias de correntes sociológicas do comportamento eleitoral, os estudos têm apontado para o caráter estratégico da decisão do voto no Brasil. A recompensa a governos por seu desempenho, especialmente em termos econômicos e de melhoria nas condições de vida, é fator que vai ao encontro de elementos clássicos da literatura que privilegia a racionalidade individual do voto, à frente de considerações atitudinais, contextuais ou de classe (Figueiredo 1991; Downs 1999).

Inserindo-se nesse debate, este artigo propõe uma análise exploratória acerca dos determinantes do voto para presidente nos dois turnos de 2014, com base nos resultados do Estudo Eleitoral Brasileiro (ESEB). Configurando um modelo geral de explicação do voto para presidente, 15 variáveis foram selecionadas a partir dos achados da literatura recente, cobrindo explicações contextuais, sociodemográficas, de avaliação retrospectiva/prospectiva, sociotrópica/egotrópica e de identidade política. As variáveis foram inseridas em um modelo logístico multinomial no primeiro turno (voto em Dilma, Aécio ou Marina), e em um modelo binário no segundo turno (voto em Dilma ou Aécio). As seções seguintes do artigo apresentam o modelo de análise, detalhando as variáveis selecionadas, e os resultados principais das regressões. Demonstramos que a avaliação do governo e a preferência partidária continuam bons preditores do voto nas eleições presidenciais. Além disso, mostramos que, diferentemente do que se supôs no período pré-eleitoral, variáveis como escolaridade e renda não são capazes de explicar a escolha do eleitor. 


\section{As eleições presidenciais de 2014 e as variáveis selecionadas}

Apesar de algumas expectativas em contrário, as eleições presidenciais de 2014 repetiram cenário semelhante ao das duas últimas disputas. Um candidato petista tido como favorito, à frente de um amplo bloco de situação, polarizou a disputa contra uma coligação encabeçada pelo PSDB e seu candidato, o senador Aécio Neves, enquanto uma terceira candidatura competitiva tentava romper esse cenário. De início, Eduardo Campos tentava se interpor entre os favoritos. Líder do Partido Socialista Brasileiro (PSB), que até setembro de 2013 participava da coalizão governista, Campos buscou se constituir como uma alternativa política capaz de manter os avanços sociais do governo petista e avançar em áreas tidas como problemáticas, como a gestão macroeconômica e o controle da corrupção. Sua trágica morte em um acidente aéreo a menos de dois meses do primeiro turno lançaria a sorte dessa candidatura de terceira via no colo de velha conhecida do eleitorado, a ex-petista Marina Silva - cuja ascensão meteórica nas pesquisas, impulsionada pela superexposição na mídia logo após o desastre que vitimou Campos, não resistiria às asperezas da campanha e às demandas da realpolitik que jurava combater. Índices significativos de aprovação ao governo (pouco abaixo dos $40 \%$ de ótimo/bom ao longo da campanha, segundo o Datafolha), alguns escândalos de corrupção (como em 2006 e 2010), defecções localizadas na base aliada e incertezas no cenário econômico (ainda com baixos índices de desemprego, no entanto) emolduraram as estratégias dos atores.

No primeiro turno, Dilma Rousseff obteve 41,6\% dos votos válidos e Aécio Neves, $33,5 \%$. O segundo turno foi marcado por um acirramento político e ideológico sem precedentes desde a histórica disputa entre Luiz Inácio Lula da Silva e Fernando Collor de Mello em 1989. Diferentemente do que fizeram em 2002, 2006 e 2010, os tucanos, que passaram a contar com o apoio de Marina Silva, adotaram uma estratégia de campanha mais agressiva, defendendo o legado do governo de Fernando Henrique Cardoso (1995-2002) e criticando duramente a gestão econômica do governo Dilma e os escândalos de corrupção que envolveram o PT e o governo desde 2005. Do outro lado, a presidente defendeu os avanços sociais obtidos nos 12 anos anteriores e apresentou o candidato da oposição como representante de um retrocesso para o país e como uma ameaça às conquistas dos últimos anos. O clima tenso entre os candidatos e as lideranças partidárias chegou às ruas e foram registrados enfrentamentos entre tucanos e petistas em algumas metrópoles do país às vésperas do segundo turno. A indefinição sobre o resultado seguiu até a apuração dos votos, que confirmou a reeleição da presidente Dilma Rousseff com 51,7\% dos votos válidos. Esse foi o resultado mais apertado de uma eleição presidencial no Brasil, e o candidato da oposição conseguiu vencer em três das cinco regiões do país (Centro-Oeste, Sudeste e Sul). Os dados podem ser conferidos nas Tabelas 1 e 2 .

Tabela 1 - Resultado da eleição presidencial de $2014,1^{\circ}$ turno (\% dos votos válidos)

\begin{tabular}{lccccc}
\hline & Dilma & Aécio & Marina & Outros & Total \\
\hline Norte & 50,1 & 28,1 & 18,7 & 3,1 & 100 \\
Centro-Oeste & 32,7 & 41,0 & 23,5 & 2,8 & 100 \\
Nordeste & 59,7 & 15,4 & 22,8 & 2,2 & 100 \\
Sul & 36,3 & 47,2 & 12,8 & 3,6 & 100 \\
Sudeste & 32,4 & 39,4 & 23,6 & 4,5 & 100 \\
Brasil & $\mathbf{4 1 , 6}$ & $\mathbf{3 3 , 5}$ & $\mathbf{2 1 , 3}$ & $\mathbf{3 , 5}$ & $\mathbf{1 0 0}$ \\
\hline
\end{tabular}

Fonte: Tribunal Superior Eleitoral. 
Tabela 2 - Resultado da eleição presidencial de 2014, $2^{\circ}$ turno (\% dos votos válidos)

\begin{tabular}{lccc}
\hline & Dilma & Aécio & Total \\
\hline Norte & 56,5 & 43,5 & 100 \\
Centro-Oeste & 42,6 & 57,4 & 100 \\
Nordeste & 71,7 & 28,3 & 100 \\
Sul & 41,1 & 58,9 & 100 \\
Sudeste & 43,8 & 56,2 & 100 \\
Brasil & $\mathbf{5 1 , 7}$ & $\mathbf{4 8 , 3}$ & $\mathbf{1 0 0}$ \\
\hline
\end{tabular}

Fonte: Tribunal Superior Eleitoral.

Levado a cabo logo após o segundo turno das eleições, o Estudo Eleitoral Brasileiro de 2014 foi realizado pelo Centro de Estudos de Opinião Pública (Cesop) da Universidade Estadual de Campinas (Unicamp) em parceria com o Instituto Brasileiro de Opinião Pública e Estatística (Ibope), responsável pela amostragem e pelo trabalho de campo do survey. A série ESEB é realizada desde 2002 e faz parte do consórcio internacional Comparative Studies of Electoral Systems (CSES), coordenado pela Universidade de Michigan. Dessa maneira, os questionários aplicados nas quatro ondas realizadas até o presente (2002, 2006, 2010 e 2014) contêm um módulo que é comum a todos os integrantes do projeto, e outro que é desenhado por pesquisadores brasileiros.

O survey de 2014 contou com amostragem nacional de 2.506 entrevistas

2 O ESEB 2014 contou ainda com uma subamostra para o Estado de São Paulo e o total de entrevistas foi de 3.136 . com eleitores ${ }^{2}$ e foi realizado entre os dias $1^{\circ}$ e 19 de novembro de 2014 . O processo de seleção da amostra foi feito em três estágios. No primeiro, os municípios foram selecionados probabilisticamente por meio do método PPT (Probabilidade Proporcional ao Tamanho), tomando como base o número de eleitores de cada município. A amostra foi estratificada por estado, e no caso de unidades da federação com regiões metropolitanas, subestratificadas em regiões metropolitanas e interior. No segundo, foram selecionados os setores censitários dentro de cada município, também pelo método PPT, e tendo como base o número de moradores de cada setor censitário. No terceiro, foi feita a seleção do entrevistado utilizando-se cotas proporcionais ao universo em função das seguintes variáveis: sexo, idade, escolaridade e ramo de atividade.

Como o nosso objetivo é identificar as distinções entre os eleitores dos principais candidatos à presidência, incorporamos na nossa análise relativa ao primeiro turno apenas os eleitores que declararam ter votado em Dilma Rousseff, Aécio Neves e Marina Silva (2.071 casos). Os eleitores que não responderam, não compareceram às urnas, não lembravam em quem votaram, votaram em branco, anularam o voto ou afirmaram ter escolhido outro candidato foram excluídos da análise. O mesmo procedimento foi adotado para os dados relativos ao segundo turno. Ou seja, comparamos apenas os eleitores declarados de Dilma Rousseff e de Aécio Neves (2.120 casos). Nas Tabelas 3 e 4 apresentamos os resultados obtidos pelo ESEB 2014 entre os que declararam ter votado no primeiro e/ou no segundo turnos.

Para a análise do voto no primeiro turno das eleições, optamos por construir um modelo estatístico utilizando a técnica da regressão logística multinomial. As categorias utilizadas foram o voto declarado em Dilma Rousseff, Aécio Neves e Marina Silva. A categoria de referência foi a declaração de voto em Dilma Rousseff. Dessa maneira, coeficientes positivos em cada uma das variáveis independentes indicam maior probabilidade do voto em Aécio Neves e em Marina Silva. Já para a análise do segundo turno, decidimos pela técnica de regressão logística binária, separando os eleitores de Dilma Rousseff e de Aécio 
Tabela 3 - Voto nas eleições presidenciais de 2014 ( $1^{\circ}$ turno), segundo o ESEB (\%)

\begin{tabular}{lc}
\hline Candidato & $\%$ \\
\hline Dilma (PT) & 47,4 \\
Aécio (PSDB) & 32,4 \\
Marina (PSB) & 11,3 \\
Outros & 1,7 \\
Brancos & 2,2 \\
Nulos & 3,3 \\
Não Sabe/Não Lembra & 0,5 \\
Não Respondeu & 1,2 \\
\hline
\end{tabular}

Fonte: ESEB 2014.

Tabela 4 - Voto nas eleições presidenciais de 2014 ( $2^{\circ}$ turno), segundo o ESEB (\%)

\begin{tabular}{lc}
\hline Candidato & $\%$ \\
\hline Dilma (PT) & 54,5 \\
Aécio (PSDB) & 39,1 \\
Brancos & 1,5 \\
Nulos & 3,7 \\
Não Sabe/Não Lembra & 0,3 \\
Não Respondeu & 1,0 \\
\hline
\end{tabular}

Fonte: ESEB 2014.

Neves. Da mesma maneira que no modelo anterior, coeficientes positivos indicam maior probabilidade do voto no candidato tucano.

As variáveis independentes foram selecionadas de acordo com a literatura discutida e refletem as hipóteses que geralmente são apresentadas nos trabalhos que buscam compreender os determinantes do voto no Brasil. Neste trabalho, reunimos as variáveis em cinco grupos: (a) Avaliação retrospectiva; (b) Avaliação prospectiva; (c) Identidade política; (d) Contexto; e (e) Socioeconômicas e Demográficas (Figura 1). Vejamos cada uma delas:

(a) Avaliação retrospectiva

1 - Avaliação da situação econômica: elaborada a partir da pergunta "na sua opinião, a atual situação econômica do Brasil está melhor, igual ou pior do que há doze meses?" As respostas foram agrupadas em três categorias (melhor, igual e pior) e a categoria de referência adotada foi a alternativa "melhor".

2 - Avaliação do governo: construída a partir da questão "na sua opinião, de uma maneira geral, o governo da presidente Dilma Rousseff nos últimos quatro anos foi ótimo, bom, ruim ou péssimo?" As respostas foram reunidas em três categorias (ótimo/bom, regular, ruim/péssimo). A resposta "regular" era possível de maneira espontânea. A categoria de referência escolhida foi a "ótimo/bom".

3 - Beneficiário do PBF: organizada a partir da pergunta "nos últimos três anos, o(a) senhor(a) ou alguém que vive em sua casa foi beneficiário (recebeu) do Programa Bolsa Família?" Os grupos foram separados entre os que responderam afirmativamente e negativamente. A categoria de referência foi os que declararam que alguém em sua casa participava do PBF. 
Figura 1 - Modelo explicativo do voto em Dilma Rousseff nas eleições de 2014

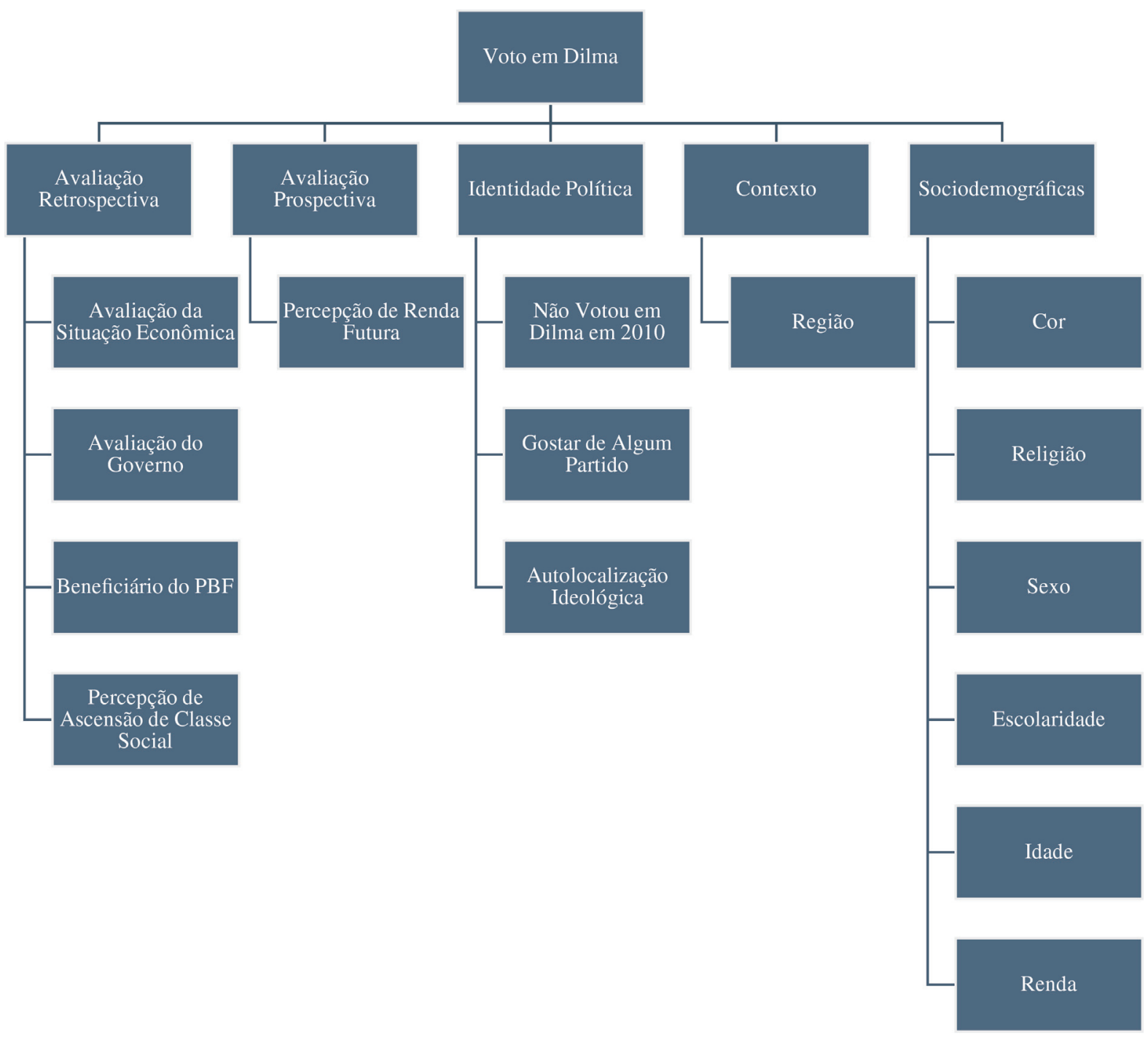

Fonte: Os autores.

4 - Percepção de ascensão de classe social: elaborada a partir de questões em que o entrevistado deveria responder se mudou de classe social nos últimos oito anos e se a alteração foi ascendente ou descendente. Separamos os respondentes em dois grupos: aqueles que afirmaram terem subido de classe e os que declararam terem descido ou não terem mudado de classe social. A categoria de referência foi composta pelos que subiram.

(b) Avaliação Prospectiva:

1 - Percepção sobre a renda futura: organizada a partir da pergunta "o(a) senhor(a) diria que nos próximos 12 meses é 'muito provável', 'provável', ‘improvável' ou 'muito improvável' que a renda familiar de seu domicílio seja fortemente reduzida?" As respostas foram agregadas em três categorias: "muito provável/provável", "não sabe" e "improvável/muito improvável”. A categoria de referência foi composta por aqueles que não acreditavam que sua renda seria fortemente reduzida nos 12 meses subsequentes.

(c) Identidade Política 
1 - Não votou em Dilma em 2010: nesta variável separamos os eleitores que votaram em Dilma Rousseff no primeiro turno das eleições presidenciais de 2010 daqueles que votaram em outros candidatos, anularam o voto, votaram em branco, não se lembraram em quem votaram ou se recusaram a responder. Foram excluídos da análise aqueles que declararam não terem votado naquela eleição. O mesmo procedimento foi adotado para a declaração de voto no segundo turno em 2010. A categoria de referência para os dois turnos foi o voto em Dilma Rousseff.

2 - Gostar de algum partido: a variável foi elaborada a partir da declaração do entrevistado de que ele gostava de algum partido mais do que dos outros e a partir da indicação de qual era esse partido. Agregamos as respostas em quatro categorias (PT, PSDB, "outros" e "sem partido"). A categoria de referência foi composta pelos "sem partido", grupo que incluiu todos aqueles que não indicaram nenhum partido preferido.

3 - Localização ideológica: a localização ideológica foi mensurada a partir da autolocalização do entrevistado em uma escala de 11 pontos ( 0 a 10), em que zero significa esquerda e dez, direita. A partir das respostas, agregamos os entrevistados em quatro grupos distintos. Na categoria "esquerda" foram colocados os que se localizaram entre zero e três. No "centro", os que se posicionaram entre quatro e seis. $\mathrm{Na}$ "direita", ficaram os que se localizaram entre sete e dez. Por fim, agrupamos todos aqueles que não se posicionaram ou que não sabiam o que era esquerda e direita na categoria "não sabe". Esta última foi usada como referência.

(d) Contexto

1 - Região: separamos os respondentes de acordo com a região do País em que residiam (Norte, Nordeste, Centro-Oeste, Sudeste e Sul). A categoria de referência foi a região Sudeste.

(e) Socioeconômicas e Demográficas

1 - Cor: agrupamos os entrevistados em dois grupos ("brancos" e "não brancos"). A categoria de referência foi "não brancos".

2 - Religião: reunimos os eleitores em três grupos (católicos, evangélicos e outras/não tem). A categoria de referência foi a composta pelos católicos.

3 - Sexo: a categoria de referência foi "masculino".

4 - Escolaridade: A partir da indicação dos entrevistados, criamos quatro grupos (Fundamental Incompleto, Fundamental Completo/Médio Incompleto, Médio Completo/Superior Incompleto e Superior Completo). A categoria de base foi "Fundamental Incompleto".

5 - Renda familiar: a partir das respostas sobre a renda familiar mensal em salários mínimos (SM), agrupamos os entrevistados em cinco grupos (até $1 \mathrm{SM}$, de 1 a 2 SM, de 2 a 5 SM, de 5 a 10 SM, mais de 10 SM). A categoria de referência foi "até $1 \mathrm{SM}$ ".

6 - Idade: variável contínua com a idade do entrevistado.

Com as variáveis de "avaliação retrospectiva" buscamos mensurar até que ponto a escolha do eleitor em 2014 refletiu uma recompensa ao governo pela melhora nas condições de vida ou devido ao PBF. Dessa forma, esperamos que avaliações positivas aumentem a probabilidade de voto na candidata à reeleição, Dilma Rousseff, tanto no primeiro quanto no segundo turnos. Com a "avaliação prospectiva", nosso objetivo é medir até que ponto as expectativas sobre o futuro econômico do eleitor refletiram na sua escolha política, em um voto econômico do tipo egotrópico. Sendo assim, imaginamos que aqueles que 
não acreditavam que sua renda fosse reduzida no futuro tenham optado por Dilma Rousseff. Já o grupo de variáveis incluído na "identidade política” busca captar até que ponto lealdades partidárias e pessoais e a autolocalização ideológica foram capazes de estruturar o voto dos eleitores. Esperamos que eleitores que votaram em Dilma em 2010, que se identifiquem com o PT e que estejam à esquerda no espectro político tenham mais probabilidade de votar na petista. A variável contextual "região" busca observar se viver em uma determinada região do País afeta o voto para a presidência independentemente de outras variáveis, como escolaridade e ser beneficiário do PBF. Dada a elevada votação dos candidatos petistas à presidência na região Nordeste desde 2006, é possível que elementos ligados à região, como $(i)$ a percepção de que a alternativa no poder desde 2003 é melhor do que qualquer outra ou (ii) a ideia de que programas do governo federal para a região possam ser retirados ou diminuídos, exerçam algum impacto na opção dos eleitores. Por fim, a análise das variáveis socioeconômicas e demográficas ajuda a compreender a existência ou não de preferências causadas por religião, sexo, idade, renda e escolaridade. O modelo explicativo é resumido na Figura 1.

\section{Resultados}

Os resultados referentes ao primeiro turno de 2014, apresentados na Tabela 5, mostram-se consistentes com os achados sobre as eleições de 2010. Com relação à avaliação retrospectiva, qualificar o desempenho do governo como regular e ruim/péssimo diminui sensivelmente a chance do voto em Dilma Rousseff. É interessante notar, porém, que a avaliação da situação econômica tanto retrospectiva quanto prospectiva -, ser beneficiário do PBF ou declarar que ascendeu socialmente não foram capazes de explicar a decisão de voto no primeiro turno. Em especial, a não significância da avaliação econômica se encontra em desacordo com o que grande parte da literatura tem apontado nos últimos anos.

As variáveis de identidade política demonstram que não ter votado em Dilma em 2010 ampliam as chances de voto em Aécio Neves e Marina Silva. Gostar do PT aumenta as chances de votar em Dilma e preferir o PSDB amplia a probabilidade de escolher Aécio Neves e também Marina Silva, ainda que com menor intensidade. Já a preferência por outros partidos que não PT e PSDB amplia a probabilidade de voto na candidata do PSB. A autolocalização ideológica também demonstra ser capaz de explicar o voto no candidato tucano: ter algum posicionamento, ainda que à esquerda, aumenta as chances de voto em Aécio com relação àqueles que não se posicionaram.

A variável região também demonstrou algum efeito. Viver no Norte amplia a chance de votar em Aécio, e morar no Nordeste reduz a probabilidade de voto no tucano - tendo como categoria de referência a região Sudeste. Já Marina Silva tem a sua probabilidade de voto diminuída entre os eleitores que vivem no Sul.

Por fim, quando controladas pelas variáveis de avaliação retrospectiva, identidade e contexto, os elementos socioeconômicos e demográficos não demonstraram muito poder para explicar as diferenças nas escolhas entre os três principais candidatos no primeiro turno. Como esperado, ser evangélico aumenta as chances de voto em Marina - assim como pertencer à categoria de escolaridade "médio completo e superior incompleto".

As análises para o voto no segundo turno apresentam resultados semelhantes (Tabela 6). Avaliar mal o governo, não ter votado em Dilma no segundo turno de 2010, gostar do PSDB e se autolocalizar à direita no espectro político ampliam as chances de voto em Aécio. Já viver no Nordeste e gostar do PT 
Tabela 5 - Regressão logística multinomial. Voto para presidente em 2014, primeiro turno

\begin{tabular}{|c|c|c|c|c|c|c|}
\hline & \multicolumn{3}{|c|}{ Aécio Neves (PSDB) } & \multicolumn{3}{|c|}{ Marina Silva (PSB) } \\
\hline & B & Sig. & $\operatorname{Exp}(B)$ & $\mathbf{B}$ & Sig. & $\operatorname{Exp}(B)$ \\
\hline \multicolumn{7}{|l|}{ Avaliação da situação econômica } \\
\hline Igual & 0,099 & 0,636 & 1,104 & 0,282 & 0,272 & 1,326 \\
\hline Pior & 0,269 & 0,256 & 1,309 & 0,339 & 0,237 & 1,404 \\
\hline \multicolumn{7}{|l|}{ Avaliação do governo } \\
\hline Regular & 1,290 & 0,000 & 3,634 & 1,253 & 0,000 & 3,500 \\
\hline Ruim/Péssimo & 2,851 & 0,000 & 17,313 & 2,560 & 0,000 & 12,940 \\
\hline Beneficiário do PBF & 0,015 & 0,936 & 1,016 & $-0,391$ & 0,096 & 0,676 \\
\hline Ascensão de classe social & $-0,148$ & 0,441 & 0,863 & $-0,368$ & 0,096 & 0,692 \\
\hline \multicolumn{7}{|l|}{ Percepção de renda futura } \\
\hline Não sabe & 0,236 & 0,344 & 1,266 & $-0,255$ & 0,430 & 1,415 \\
\hline Muito Provável/Provável redução & 0,263 & 0,142 & 1,301 & 0,347 & 0,103 & 0,775 \\
\hline Não votou em Dilma em 2010 & 1,322 & 0,000 & 3,751 & 0,963 & 0,000 & 2,619 \\
\hline \multicolumn{7}{|l|}{ Gostar de algum partido } \\
\hline PT & $-1,667$ & 0,000 & 0,189 & $-1,243$ & 0,000 & 0,289 \\
\hline PSDB & 2,372 & 0,000 & 10,718 & 1,696 & 0,001 & 5,451 \\
\hline Outros & 0,513 & 0,080 & 1,670 & 0,938 & 0,004 & 2,555 \\
\hline \multicolumn{7}{|l|}{ Autolocalização ideológica } \\
\hline Esquerda & 0,697 & 0,044 & 2,008 & 0,621 & 0,104 & 1,861 \\
\hline Centro & 0,564 & 0,010 & 1,758 & 0,369 & 0,142 & 1,446 \\
\hline Direita & 0,631 & 0,002 & 1,879 & $-0,451$ & 0,093 & 0,637 \\
\hline \multicolumn{7}{|l|}{ Região } \\
\hline Norte & 0,615 & 0,046 & 1,849 & $-0,585$ & 0,220 & 0,557 \\
\hline Nordeste & $-0,844$ & 0,001 & 0,430 & 0,035 & 0,891 & 1,036 \\
\hline Centro-oeste & 0,410 & 0,187 & 1,507 & $-0,440$ & 0,296 & 0,644 \\
\hline Sul & 0,414 & 0,079 & 1,513 & $-0,917$ & 0,015 & 0,400 \\
\hline Cor (Branco) & 0,344 & 0,057 & 1,411 & $-0,317$ & 0,161 & 0,728 \\
\hline \multicolumn{7}{|l|}{ Religião } \\
\hline Evangélica & 0,051 & 0,801 & 1,053 & 1,095 & 0,000 & 2,990 \\
\hline Outras/não tem & $-0,096$ & 0,718 & 0,908 & $-0,006$ & 0,985 & 0,994 \\
\hline Sexo (masculino) & $-0,176$ & 0,298 & 0,838 & $-0,290$ & 0,157 & 0,749 \\
\hline \multicolumn{7}{|l|}{ Escolaridade } \\
\hline Fund comp/médio incomp & 0,099 & 0,683 & 1,104 & 0,089 & 0,771 & 1,093 \\
\hline Médio comp/Sup. Incomp & 0,088 & 0,695 & 1,091 & 0,604 & 0,025 & 1,830 \\
\hline Superior completo & $-0,072$ & 0,824 & 0,930 & 0,306 & 0,436 & 1,359 \\
\hline \multicolumn{7}{|l|}{ Renda familiar } \\
\hline De 1 a 2 salários mínimos & 0,074 & 0,810 & 1,077 & $-0,247$ & 0,490 & 0,781 \\
\hline De 2 a 5 salários mínimos & 0,475 & 0,112 & 1,608 & 0,349 & 0,304 & 1,417 \\
\hline De 5 a 10 salários mínimos & 0,693 & 0,066 & 2,000 & 0,503 & 0,253 & 1,654 \\
\hline Mais de 10 salários mínimos & 0,531 & 0,284 & 1,701 & $-0,007$ & 0,991 & 0,993 \\
\hline Idade & $-0,003$ & 0,617 & 0,997 & $-0,004$ & 0,569 & 0,996 \\
\hline
\end{tabular}

Notas: $\mathrm{N}=1.388$; Pseudo $\mathrm{R} 2=0,572 ; \log$ pseudolikelihood $=1772,71$. A categoria de referência foi o voto em Dilma Rousseff.

Fonte: Os autores, a partir do ESEB 2014. 
Tabela 6 - Regressão logística binária. Voto para presidente em 2014, segundo turno

\begin{tabular}{|c|c|c|c|}
\hline & \multicolumn{3}{|c|}{ Aécio Neves (PSDB) } \\
\hline & B & Sig. & $\operatorname{Exp}(B)$ \\
\hline \multicolumn{4}{|l|}{ Avaliação da situação econômica } \\
\hline Igual & $-0,125$ & 0,555 & 0,883 \\
\hline Pior & 0,229 & 0,322 & 1,258 \\
\hline \multicolumn{4}{|l|}{ Avaliação do governo } \\
\hline Regular & 1,328 & 0,000 & 3,773 \\
\hline Ruim/Péssimo & 2,987 & 0,000 & 19,819 \\
\hline Beneficiário do PBF & $-0,425$ & 0,027 & 0,654 \\
\hline Ascensão de classe social & $-0,237$ & 0,202 & 0,789 \\
\hline \multicolumn{4}{|l|}{ Percepção de renda futura } \\
\hline Não sabe & 0,172 & 0,494 & 1,188 \\
\hline Muito Provável/Provável redução & 0,248 & 0,158 & 1,281 \\
\hline Não votou em Dilma em 2010 & 1,554 & 0,000 & 4,732 \\
\hline \multicolumn{4}{|l|}{ Gostar de algum partido } \\
\hline PT & $-2,332$ & 0,000 & 0,097 \\
\hline PSDB & 1,786 & 0,000 & 5,968 \\
\hline Outros & 0,384 & 0,165 & 1,468 \\
\hline \multicolumn{4}{|l|}{ Autolocalização ideológica } \\
\hline Esquerda & 0,384 & 0,257 & 1,469 \\
\hline Centro & 0,392 & 0,065 & 1,480 \\
\hline Direita & 0,562 & 0,007 & 1,754 \\
\hline \multicolumn{4}{|l|}{ Região } \\
\hline Norte & 0,030 & 0,929 & 1,030 \\
\hline Nordeste & $-0,559$ & 0,014 & 0,572 \\
\hline Centro-oeste & 0,362 & 0,246 & 1,437 \\
\hline Sul & 0,316 & 0,191 & 1,371 \\
\hline Cor (Branco) & 0,178 & 0,323 & 1,195 \\
\hline \multicolumn{4}{|l|}{ Religião } \\
\hline Evangélica & 0,099 & 0,625 & 1,104 \\
\hline Outras/não tem & $-0,262$ & 0,310 & 0,769 \\
\hline Sexo (masculino) & 0,073 & 0,664 & 1,075 \\
\hline \multicolumn{4}{|l|}{ Escolaridade } \\
\hline Fund. comp/médio incomp. & $-0,148$ & 0,548 & 0,862 \\
\hline Médio comp/Sup. Incomp & 0,077 & 0,729 & 1,080 \\
\hline Superior completo & 0,129 & 0,685 & 1,137 \\
\hline \multicolumn{4}{|l|}{ Renda familiar } \\
\hline De 1 a 2 salários mínimos & $-0,014$ & 0,963 & 0,986 \\
\hline De 2 a 5 salários mínimos & 0,215 & 0,455 & 1,240 \\
\hline De 5 a 10 salários mínimos & 0,080 & 0,829 & 1,083 \\
\hline Mais de 10 salários mínimos & 0,526 & 0,288 & 1,691 \\
\hline Idade & 0,004 & 0,575 & 1,004 \\
\hline
\end{tabular}

Notas: $\mathrm{N}=1.365$; Pseudo $\mathrm{R} 2=0,629$; $\log$ pseudolikelihood $=993,522$. A categoria de referência foi o voto em Dilma Rousseff.

Fonte: Os autores, a partir do ESEB 2014. 
reduzem a probabilidade de voto no candidato tucano. A principal diferença com relação ao primeiro turno encontra-se na variável relacionada ao PBF. No segundo turno, essa variável mostrou-se estatisticamente significativa: participar ou contar com alguém da família que integra o PBF ampliou a chance de voto na candidata petista.

\section{Conclusões}

Os resultados apresentados reforçam os argumentos no sentido do caráter retrospectivo do comportamento do eleitor nas eleições presidenciais, destacado por diversos autores nos últimos anos (Meneguello 2011; Rennó \& Cabello 2010; Peixoto \& Rennó 2011; Nicolau 2014a; 2014b). A avaliação em relação à gestão de Dilma Rousseff se mostrou um ótimo preditor do voto, em ambos os turnos. No primeiro, uma avaliação regular do governo aumentava a probabilidade de voto em Aécio ou Marina em mais de três vezes, em comparação aos que classificavam a gestão como ótima ou boa; se a avaliação fosse ruim ou péssima, essa proporção superava 17 vezes no caso de voto em Aécio, e 12 vezes no caso de Marina. Os dois principais adversários do governo disputaram entre si, portanto, os votos de um estoque de eleitores insatisfeitos com a administração petista. No segundo turno, o impacto dessa variável retrospectiva se mostrou ainda mais forte.

O julgamento sobre o desempenho do governo esteve dissociado, no entanto, da avaliação sobre a situação econômica do país nos 12 meses anteriores à pesquisa: $46 \%$ dos eleitores avaliavam o governo como ótimo/bom, mas apenas um quarto considerava que a economia havia melhorado no último ano (ver tabela descritiva do ESEB, no Anexo I). Essa dissociação entre as avaliações retrospectivas do governo e da economia foi, portanto, decisiva para a reeleição de Dilma. Embora somente análises mais refinadas possam fornecer respostas mais precisas a esse aparente descompasso, pode-se especular sobre alguns fatores. À primeira vista, grande parte do eleitorado não responsabilizava o governo pelos problemas econômicos, então amplamente divulgados pelos meios de comunicação. Talvez uma das explicações resida no fato de que a deterioração econômica não afetava o indicador mais sensível para a grande maioria do eleitorado: as taxas de desemprego, então inferiores a 5\%. Por outro lado, as estratégias de comunicação do governo e da candidata podem ter se mostrado eficientes na construção de um discurso que situava no cenário internacional as raízes das dificuldades, mostrando que o governo fazia o que era possível dentro de um contexto externo recessivo. Os dados relativos à percepção da renda futura parecem confirmar essa interpretação, pois acreditar que a renda domiciliar seria fortemente reduzida nos 12 meses subsequentes não foi capaz de predizer o voto em nenhum dos dois turnos.

A avaliação sobre outras políticas públicas, a despeito da condução econômica, também deve ter impulsionado a avaliação positiva do governo federal, transformando-se em variável relevante para o voto em Dilma. Pode ser entendida nessa linha a força da variável contextual: mantidas constantes as demais variáveis, residir no Nordeste potencializou o voto em Dilma e diminuiu as chances de voto em Aécio, nos dois turnos. Se consideramos que a participação do eleitor (ou de alguém de sua residência) no Programa Bolsa Família se mostrou relevante apenas no segundo turno, é razoável pensar que outras políticas do governo federal - como as que visam impulsionar o desenvolvimento do Nordeste ou as mais impactantes na região - se tornaram tão ou mais importantes como balizadoras do voto quanto o programa de transferência de renda. Com resultados diferentes entre os dois turnos, os dados do ESEB 2014 não são conclusivos acerca dos efeitos eleitorais do PBF, mantendo em aberto o debate dos últimos anos (Licio, Rennó \& Castro 2009; Bohn 2011; Nicolau 
2014b; Zucco 2013; 2015). É possível, porém, que o aparecimento do efeito eleitoral do PBF no segundo turno esteja ligado ao acirramento da disputa eleitoral e das reiteradas afirmações por parte da campanha petista de que os programas sociais implantados nos doze anos anteriores estariam sob ameaça com uma eventual vitória do candidato tucano. No entanto, apenas pesquisas de tipo painel seriam capazes de captar as alterações provocadas por estímulos da campanha sobre o eleitor.

As variáveis políticas se mostraram relevantes. A identificação com o PT e com o PSDB se confirmaram como importantes atalhos cognitivos para a decisão de voto, corroborando o efeito estruturador do sistema partidário assumido pelas duas legendas desde 1994 (Limongi \& Cortez 2010; Melo \& Câmara 2012; Nicolau 2014b) e reforçando a ideia de que os partidos importam para a escolha do eleitor. No primeiro turno, a identificação com o PSDB aumentava as chances de voto não só em Aécio, mas também em Marina, comprovando que os dois candidatos disputavam na mesma "raia" de eleitores insatisfeitos com o governo e/ou avessos ao PT, e sugerindo que a lealdade dos tucanos talvez seja menor que a dos petistas. A autolocalização ideológica apresentou resultados contraditórios. No primeiro turno, ter qualquer posicionamento ideológico elevou as chances do voto em Aécio. Já no segundo, apenas estar à direita (quando comparado ao eleitor que não se posicionou na escala) ampliou a possibilidade de escolher o candidato do PSDB, enquanto o autoposicionamento à esquerda não elevou as chances de voto em Dilma. Como destacado por outros autores (Rennó \& Cabello 2010), essa é uma variável que deve ser utilizada com bastante precaução, dadas as dificuldades metodológicas envolvidas.

Sobre Marina Silva, vale destacar que seu discurso sobre uma "nova política" e as movimentações em torno da criação da Rede Sustentabilidade não foram eficientes na atração do eleitorado jovem, supostamente refratário à polarização entre PT e PSDB. Os dados sugerem características bem mais personalistas como explicação da adesão à terceira via: comparado aos católicos, o eleitorado evangélico tinha uma probabilidade três vezes maior de votar em Marina do que em Dilma. Como essa relação não se manteve para o voto em Aécio no segundo turno, é razoável concluir que Marina Silva conseguiu capitalizar pessoalmente a adesão de amplos segmentos evangélicos do eleitorado.

De modo geral, no entanto, as variáveis socioeconômicas e demográficas tiveram um rendimento bem mais reduzido do que os demais fatores explicativos. Ao contrário do que se poderia supor a partir das pesquisas pré-eleitorais, a renda familiar não se mostrou uma variável significativa como preditora do voto em 2014, fragilizando argumentos assentados em perspectivas de classe, como os de Singer (2009). Os dados sobre renda e escolaridade não suportam afirmações peremptórias no sentido de apontar que o eleitorado de Dilma se concentrava nos estratos mais baixos da pirâmide social. A percepção de ascensão social, destacada por Peixoto e Rennó (2011) como fator importante para o voto em Dilma em 2010, não se mostrou variável relevante em 2014. Os possíveis efeitos eleitorais dos processos de mobilidade social que afetaram milhões de brasileiros a partir de 2003 seguem como questão não respondida pela literatura.

Como conclusão mais geral, este artigo de caráter exploratório reforça argumentos de trabalhos anteriores que apontam a avaliação do governo, a preferência partidária e o voto no pleito anterior como bons preditores do voto nas eleições presidenciais. Entretanto, o caráter retrospectivo do comportamento do eleitor, recompensando ou punindo o candidato do governo a partir da análise de seu desempenho, mostra-se um fator mais complexo do que se 
supunha, na medida em que não se restringe à avaliação do cenário econômico ou à participação direta nos programas de transferência de renda.

Oswaldo E. do Amaral (oswamaral@gmail.com) é Doutor em Ciência Política pela Universidade Estadual de Campinas (Unicamp) e professor do Departamento de Ciência Política e do Programa de Pós-Graduação em Ciência Política da mesma universidade. Vínculo Institucional: Universidade Estadual de Campinas, Campinas, SP, Brasil.

Pedro Floriano Ribeiro (pfr23@cam.ac.uk) é Doutor em Ciência Política pela UFSCar, professor do Programa de PósGraduação em Ciência Política da mesma universidade, e professor visitante na Universidade de Cambridge (2015-2016). Vínculo Institucional: Cátedra Celso Furtado de Estudos Brasileiros do St. John's College, Universidade de Cambridge, Cambridge, Reino Unido.

\section{Referências}

Bohn, S.R., 2011. Social Policy and Vote in Brazil: Bolsa Família and the Shifts in Lula's Electoral Base. Latin American Research Review, 46(1), pp.54-79.

Braga, M.S.S. \& Pimentel Jr., J., 2011. Os partidos políticos brasileiros realmente não importam? Opinião Pública, 17(2), pp.271-303 DOI: 10.1590/S0104-62762011000200001

Carreirão, Y.S., 2002. A decisão de voto nas eleições presidenciais brasileiras. Florianópolis/Rio de Janeiro: EdUFSC/FGV. , 2007. Identificação ideológica, partidos e voto na eleição presidencial de 2006. Opinião Pública, 13(2), pp.307-339. DOI: $10.1590 / \mathrm{S} 0104-62762007000200004$

Carreirão, Y.S. \& Kinzo, M.D., 2004. Partidos políticos, preferência partidária e decisão eleitoral no Brasil (1989/2002). Dados, 47(1), pp.131-168. DOI: 10.1590/S0011-52582004000100004

Downs, A., 1999. Uma teoria econômica da democracia. São Paulo: Edusp.

Figueiredo, M., 1991. A decisão do voto: democracia e racionalidade. São Paulo: Editora Sumaré.

Holzhacker, D. \& Balbachevsky, E., 2007. Classe, ideologia e política: uma interpretação dos resultados das eleições de 2002 e 2006. Opinião Pública, 13(2), pp.283-306. DOI: 10.1590/S0104-62762007000200003

Hunter, W. \& Power, T., 2007. Rewarding Lula: Executive Power, Social Policy, and the Brazilian Elections of 2006. Latin American Politics and Society, 49(1), pp.1-30. DOI: 10.1111/j.1548-2456.2007.tb00372.x

Licio, E.C., Rennó, L. \& Castro, H.C.O., 2009. Bolsa Família e voto na eleição presidencial de 2006: em busca do elo perdido. Opinião Pública, 15(1), pp.31-54. DOI: 10.1590/S0104-62762009000100002

Limongi, F. \& Cortez, R., 2010. As eleições de 2010 e o quadro partidário. Novos Estudos, 88, pp.21-37. DOI: 10.1590/S0101-33002010000300002

Melo, C.R. \& Câmara, R., 2012. Estrutura da Competição pela Presidência e Consolidação do Sistema Partidário no Brasil. Dados, 55(1), pp.71-117. DOI: 10.1590/S0011-52582012000100003

Meneguello, R., 2007. Tendencias eleitorais ao fim de 21 anos de democracia. In: M.A. Saez, \& C.R. Melo. A democracia brasileira: balanços e perspectivas para o século XXI. Belo Horizonte: UFMG.

Nicolau, J., 2007. An Analysis of the 2002 Presidential Elections using Logistic Regression. Brazilian Political Science Review, 1(1), pp.125-135.

, 2014a. Vermelhos e Azuis: um estudo sobre os determinantes do voto nas eleições presidenciais brasileiras (2002-2010). In: $9^{\circ}$ Encontro da Associação Brasileira de Ciência Política. Brasília.

, 2014b. Determinantes do voto no primeiro turno das eleições presidenciais brasileiras de 2010: uma análise exploratória. Opinião Pública, 20(3), pp.311-325. DOI: 10.1590/1807-01912014203311

Nicolau, J. \& Peixoto, V., 2007. Uma disputa em três tempos: uma análise das bases municipais das eleições presidenciais de 2006. In $31^{\circ}$ Encontro Anual da ANPOCS. Caxambu.

Peixoto, V. \& Rennó, L., 2011. Mobilidade social ascendente e voto: as eleições presidenciais de 2010 no Brasil. Opinião Pública, 17(2), pp.304-332. DOI: 10.1590/S0104-62762011000200002

Rennó, L., 2007. Escândalos e voto: as eleições presidenciais brasileiras de 2006. Opinião Pública, 13(2), pp.260-282. DOI: $10.1590 /$ S0104-62762007000200002

Rennó, L. \& Cabello, A., 2010. As bases do lulismo: a volta do personalismo, realinhamento ideológico ou não alinhamento?. Revista Brasileira de Ciências Sociais, 25(74), pp.39-60. DOI: 10.1590/S0102-69092010000300003

Ribeiro, E.; Carreirão, Y.S. \& Borba, J., 2011. Sentimentos partidários e atitudes políticas entre os brasileiros. Opinião Pública, 17(2), pp.336-368. DOI: 10.1590/S0104-62762011000200003

Singer, A., 2009. Raízes sociais e ideológicas do lulismo. Novos Estudos, 85, pp.83-102. DOI: 10.1590/S0101-33002009000300004

Soares, G.A.D. \& Terron, S., 2008. Dois Lulas: a geografia eleitoral da reeleição (explorando conceitos, métodos e técnicas de análise geoespacial). Opinião Pública, 14(2), pp.269-301. DOI: 10.1590/S0104-62762008000200001

Terron, S.L. \& Soares, G.A.D., 2010. As bases eleitorais de Lula e do PT: do distanciamento ao divórcio. Opinião Pública, 16(2), pp.310-337. DOI: 10.1590/S0104-62762010000200002

Veiga, L., 2013. Economic Voting in an Age of Growth and Poverty Reduction: Electoral Response in Latin America (1995-2010). Working Paper, Center for the Study of Democracy, University of California, Irvine. 
Zucco Jr., C. 2008. The Presidents `New’ Constituency: Lula and the pragmatic vote in Brazil’s 2006 presidential election. Journal of Latin American Studies, 40(1), pp.29-49. DOI: 10.1017/S0022216X07003628

2013. When Payouts Pay Off: Conditional Cash Transfers and Voting Behavior in Brazil 2002-10. American Journal of Political Science, 57(4), pp.810-822. DOI: 10.1111/ajps.12026

2015. The Impacts of Conditional Cash Transfers in Four Presidential Elections (2002-2014). Brazilian Political Science Review, 9(1), pp.135-149. DOI: 10.1590/1981-38212014000200006

\begin{abstract}
The paper proposes an exploratory analysis on the determinants of voting for presidency in the two rounds of 2014' Brazilian elections, based on the results of the Brazilian Electoral Study (ESEB). From the most relevant findings of the extensive recent literature on the subject, we outlined a general explanatory model of voting for president, with 15 variables covering contextual, sociodemographic, retrospective/prospective evaluation, sociotropic/egotropic and political identity explanations. The variables were included in a multinomial logistic model in the first round (vote for Dilma, Aécio or Marina), and in a binary logistic model in the second round (vote for Dilma or Aécio). The results indicate the retrospective features of voting behavior in the last presidential election: the evaluation on the Dilma Rousseff's government proved to be a good predictor of the vote in both rounds. The judgment on the government's performance has been dissociated, however, of the assessment about the economic situation of the country, suggesting that the perceptions on other public policies must have driven the positive evaluation of the government. The party identification was confirmed as an important cognitive shortcut, the Bolsa Familia had significant effects only in the second round, and sociodemographic variables showed little relevance. The retrospective nature of voting behavior, rewarding or punishing the government's candidate based on the analysis of its performance, seems to be a more complex factor than previously thought, as it is not restricted to the evaluation of the economic scenario or the direct participation of the voter in the Bolsa Família Program.
\end{abstract}

KEYWORDS: ESEB; 2014' presidential elections; voting behavior; vote; Dilma Rousseff.

License information: This is an open-access article distributed under the terms of the Creative Commons Attribution License (CC-BY-NC 4.0), which permits unrestricted use, distribution, and reproduction in any medium, provided the original work is properly cited. 


\section{Anexo 1}

Tabela 1A - Tabela descritiva

\begin{tabular}{lc}
\hline Variáveis & Porcentagem \\
\hline Avaliação da situação econômica (12 meses) & 24,7 \\
Melhor & 47 \\
Igual & 28,3 \\
Pior & \\
N (2.449) & \\
\hline Avaliação do governo (últimos 4 anos) & 45,9 \\
Ótimo/Bom & 31,8 \\
Regular & 22,3 \\
Ruim/péssimo & \\
N (2.475) & 29,7 \\
\hline Beneficiário (família) do PBF (últimos 3 anos) & \\
N (2.459) & 28,7 \\
\hline Ascendeu de classe social nos últimos oito anos & \\
N (2.506) & \\
\hline Probabilidade de forte redução da renda (próx. 12 meses) & 318 \\
Muito provável/provável & 39,7 \\
Não sabe & \\
Muito improvável/improvável & \\
N (2.485) & \\
\hline Não votou em Dilma em 2010 (1 ${ }^{\circ}$ turno) & \\
N (2.064) & \\
\hline Não votou em Dilma em 2010 (2o turno) & \\
N (1.973) & \\
\hline & \\
\hline
\end{tabular}

Gostar de algum partido

Não gosto

68,2

PT

PSDB

Outros

$\mathrm{N}(2.506)$

Localização ideológica

Não sabe

Esquerda 7,9

Centro

21,5

Direita

$\mathrm{N}(2.424)$

Região

Sudeste

Norte

Nordeste

Centro-Oeste 
$\mathrm{N}(2.506)$

Cor

Branco

Não Branco

60,6

$\mathrm{N}$ (2.488)

Religião

Católica

62,8

Evangélica

24

Outras/Não tem

13,2

$\mathrm{N}(2.496)$

Sexo

Masculino

Feminino

$\mathrm{N}(2.506)$

Escolaridade

Fundamental incompleto

Fund. comp/Médio Inc.

20,2

Médio comp/ Sup Inc.

Superior completo

9,2

$\mathrm{N}(2.506)$

Renda familiar

Até 1 salário mínimo

De 1 a 2 salários mínimos

De 2 a 5 salários mínimos

45,3

De 5 a 10 salários mínimos

11,3

Mais de 10 salários mínimos

3,5

$\mathrm{N}(2.202)$

Idade (média)

41,44

$\mathrm{N}(2.506)$

Fonte: ESEB 2014. 